\title{
Overall survival and prognostic factors prostate cancer in Kurdistan Province-Iran: a population-based study (2011-2018)
}

Mohammad Aziz Rasouli ${ }^{1,2}$, Ghobad Moradi ${ }^{1,2}$, Bushra Zareie ${ }^{3}$, Heshmatollah Sofimajidpour ${ }^{1,4^{*}}$, Sima Tozandehjani ${ }^{5}$, Hedyeh Zafari ${ }^{5}$, Fatemeh Gholami ${ }^{6}$, Sonia Shahsavari ${ }^{1}$, Parisa Hassani ${ }^{5}$ and Mahshid Mohammadian ${ }^{7}$

\begin{abstract}
Background: The population-based survival rate is affected by the quality and effectiveness of health care systems. Overall, the survival of prostate cancer (PC) patients has improved over the past two decades worldwide. This study aimed to determine the overall survival rate and correlate it with the prognostic factors in patients with PC diagnosed in Kurdistan province.
\end{abstract}

Methods: In a retrospective cohort study, 410 PC patients registered in Kurdistan province population-based cancer registry from March 2011 to 2018 were recruited. Kaplan-Meier method and log-rank test were used to analyze the overall survival rates of PC patients. A Multivariate Cox regression model was used to determine adjusted hazard ratios for different variables.

Results: Of 410 patients with PC, 263 (64.1\%) died within seven years due to the disease. The 1, 3, and 5 years survival rates were 93, 64.1, and 40.7\%, respectively. According to the results of multiple Cox regression, the following factors were significantly related to $P C$ survival: age at diagnosis ( $\geq 81$-years old) ( $\mathrm{HR}=2.23,95 \% \mathrm{Cl}: 1.23-4.42)$ and $71-80$ years old was ( $H R=1.26,95 \%$ Cl: 1.12-2.31), occupation (employee) $(H R=0.42,95 \%$ Cl: 0.20-0.87), educational level: academic ( $H R=0.78,95 \%$ Cl: 0.64-0.91), AJCC stage of disease ( $H R=2.18,95 \% \mathrm{Cl}: 1.9-3.68)$, Gleason score $\geq 9(H R=7.12$, $95 \% \mathrm{Cl}: 5.35-10.28)$, and Gleason score $=8(\mathrm{HR}=4.16,95 \% \mathrm{Cl}: 2.50-6.93)$. There was less mortality rate among the patients who had received active care, radical prostatectomy, radiotherapy, combined treatment, and orchiectomy had a lower mortality rate than those who received no treatment $(P<0.05)$.

Conclusions: This study demonstrated that factors such as age at diagnosis, level of education, occupation, AJCC stage of disease, Gleason score, and type of treatments were influential factors in the survival of PC patients in Kurdistan province and needed more attention.

Keywords: Survival, Prostate Cancer, Population-Based Study, Kurdistan, Iran

\section{Introduction}

Prostate cancer (PC) is the second most prevalent cancer and the cause of the sixth cancer-caused death in men

*Correspondence: Hsmajidpour@gmail.com

${ }^{1}$ Social Determinants of Health Research Center, Research Institute for Health Development, Kurdistan University of Medical Sciences, Sanandaj, Iran

Full list of author information is available at the end of the article worldwide [1]. The prevalence and mortality rate of the disease is not similar between countries, and $75 \%$ of the cases happen at the age above 65 years old [2-4]. Cancer is the third most prevalent cancer in men and the sixth 
most prevalent cancer in Iran, so that it constitutes 7-9\% of total cancer cases [5-7].

The prevalence of $\mathrm{PC}$ is not the same between different countries and races [8-10]. The difference is due to different reasons such as genetic capacity, exposure to the unknown environmental risk factor, differences in health care models, socioeconomic factors, cancer registration system, etc. [8-10]. Studies on cancers and determining probability and survival distribution of cancer patients based on demographical and clinical variables of patients are critical. To this end, survival analysis models can be used. Considering that long-term survival following prostate cancer treatment is widespread, it is crucial to estimate the survival rate and prepare the ground to meet the unique requirements of these patients [11-13].

Studies on estimating PC survival are growing. However, despite the ever-increasing recognition of the longterm outcomes of prostate cancer diagnosis, research works on this field are still disorganized [13, 14]. In Iran, the survival rate of $\mathrm{PC}$ is mainly based on the information of hospital files, so the five-year survival rate, according to some studies, is about $36 \%$ [15]. The survival rate based on population is affected by the quality and effectiveness of health care systems. In general, the survival rate of PC patients has been growing over the past few decades, especially in European countries [16, 17]. However, this progress is not compatible between countries, races, and socioeconomic groups. A deprivation gap was observed among patients with prostate cancer diagnosed in Scotland during 1996-2000 [17]..

The aim of assessing survival is to determine its effect on the patient, health system, and clinical care policies gap in post-treatment; Estimating resources to help patients achieve optimal health; increasing their quality of life, and survival after treatment is a significant issue of general health services.

\section{Materials and methods}

In this retrospective cohort study, 410 patients with PC were collected from the cancer registry system in the Kurdistan University of Medical Sciences from 2011 to 2018. Kurdistan is a province located in the western region of Iran and constitutes eight counties. The majority of the residents of this province are farmers and ranchers. In the national census in 2016, the overall population of this province was estimated as 1,603,000, with $71 \%$ of them lived in urban areas, and $17.5 \%$ of them were over 50 years old. Most of the residents of the province are of Kurdish ethnicity.

The study was conducted from March 20, 2011, to March 19, 2018, in Kurdistan based on a primary diagnosis of histopathology and cancer registration system. In addition, the study was a population-based work.
Diagnosis and registration were based on the International Categorization of Diseases (ICD10) and anatomic position of prostate cancer (C84). The required data were collected from Kurdistan Province Cancer Registration System. Data gathering was done in September 2019 (cutoff date).

The primary source data of PC patients were obtained from the cancer registry system. Other required data were collected from patients' medical records, pathology reports, and the death system. Trained interviewers conducted an additional telephone survey to collect data, including survival status, age (at diagnosis), sex, occupation, level of education, marital status, place of residence, smoking and alcohol history, health status at the time of referring to the hospital, the date of death, and family history of PC. Pathologic data, including patients' information, included local tumor, Gleason score, and type of treatment (based on the medical and pathological report).

Survival time was measured from the diagnosis to death or the last follow-up. The subjects were studied in terms of age at diagnosis ( $\leq 60$-years, $61-70$ years, $71-80$ years, and $\geq 81$-years old), occupation (unemployed/ retired, worker, self-employed, employee), education level (college, high school, junior high school, illiterate) marital status, and domicile. Based on the Gleason score, the tumors were categorized as low $(\leq 6)$, moderate $[7,8]$, and high $(\geq 9)$. Based on AJCC measures, the tumor stage was categorized as I, II, III, and IV, and the type of treatment included active surveillance, radical prostatectomy, radiotherapy, radiotherapy plus radical prostatectomy, orchiectomy, androgen therapy, and no treatment.

\section{Data analyses}

The 1,3 , and 5 years' survival rate and median of survival were investigated based on the variables under study. The difference in survival rate was measured for the subgroups using the log-rank test. Using the Kaplan-Meier method, overall survival, age at diagnosis, Gleason score, tumor stage, and type of treatment were demonstrated on a curve.

Univariable and multivariable regression Cox proportional hazard models were executed. To select and shrink the selected predictors according to their relative contribution to the final model, a least absolute shrinkage and selection operator (LASSO) method was performed [18]. For inclusion in a multivariate model, all those variables which had a p-value of less than 0.10 or were previously well-known confounders in such analysis were included in multivariate analysis in a stepwise approach. Internal validation was used by the bootstrap method, in which new datasets are created by random drawing from the sample with replacement [19]. The whole modeling 
process, i.e., developing a Cox regression model with a LASSO penalty, was reiterated in each of these new datasets.

The assumptions of the hazard proportionality have been tested by graphical methods (log (s) $t \mathrm{vs}$. time) and Shoenfield residuals ph test [20]. There were no violations of the proportionality assumption for any of the covariates included in the PC-specific models. $P<0.05$ was considered statistically significant. All statistical analyses were performed using Stata16.0 software (StataCorp, College Station, TX).

\section{Results}

Of 410 patients with PC, 263 (64.1\%) died within seven years due to the disease. The age at diagnosis was $68.3 \pm 8.24$ years, and 56 individuals (13.7\%) were younger than 60 years. The majority were city dwellers, $50.5 \%$ were self-employed, and $6.6 \%$ had an academic degree. In addition, 30.2 and $2.7 \%$ of the participants had a history of smoking and drinking, respectively. In 152 cases (37.1\%), the tumor stage was III, and IV in 42 cases (10.2\%). Gleason's score of 114 cases $(27.8 \%)$ was equal to 8 and $\geq 9$ for 117 cases $(28.5 \%)$. As to the type of treatment, 30 cases $(7.3 \%)$ did not receive any treatment, 63 cases $(15.4 \%)$ had active surveillance, 87 cases $(21.2 \%)$ had radiotherapy, and 86 cases $(21 \%)$ had orchiectomy (Table 1).

The results indicated that 1,3 , and 5 years' survival rate was $93,64.1$, and $40.7 \%$, respectively, with mid survival of 49 months (95\% CI 55.6-49) (Fig. 1). The log-rank test indicated that the survival rate of prostate cancer was different depending on diagnosis time $(P<0.001)$ (Fig. 2$)$, domicile $(P=0.022)$, job $(P=0.003)$, an education level ( $P=0.002)$, underlying disease $(P=042)$, the position of tumor $(P<0.001)$ (Fig. 3$)$, Gleason score $(P<0.001)$ (Fig. 4$)$, and type of treatment $(P<0.001)$. On the other hand, the survival rate was not significantly related to marital status, history of smoking and drinking, and history of prostate cancer in the family $(P>0.05)$ (Table 1$)$.

Multiple Cox regression analysis results showed that individuals older than $\geq 81$-years old had a lower survival rate $(\mathrm{HR}=2.23,95 \% \mathrm{CI}: 1.23-4.42, P=0.009)$. In addition, the hazard rate of $P C$ in individuals aged 71-80 years was 1.26 times higher than that of age group younger than $\leq 60$-years old. Univariable regression results indicated that individuals living in the city had a higher survival rate than those living in rural areas $(\mathrm{HR}=0.74,95 \% \mathrm{CI}$ : $0.5-0.97, P=0.024)$. However, multiple regression results indicated no significant difference $(P=0.067)$, and the survival rate in individuals with a university degree was higher $(\mathrm{HR}=0.78,95 \% \mathrm{CI}$ : 0.6-0.91, $P=0.042)$. Multiple Cox regression results indicated that death hazard in individuals with tumor stage III was equal to 1.45 , and that of individuals with tumor state IV was equal to 2.18. The mortality hazard rate in individuals with a Gleason score of 8 was equal to 4.16 (95\%CI: $250-6.93, P=0.012$ ), and that of individuals with a Gleason score $\geq$ of 9 was 7.14 (95\% CI: $5.35-10.28, P=0.002$ ). One variable and multivariate regression results showed that individuals who received active care, radical prostatectomy, radiotherapy, combined treatment, and orchiectomy had a lower mortality rate than those who received no treatment. However, those who received ADT treatment did not have a significantly different survival rate (Table 2 ).

\section{Discussion}

The results demonstrated that the age at diagnosis, occupation, education, AJCC stage of disease, Gleason score, and treatment type were influential factors in PC's survival rate in Kurdistan Province. The survival rate of 1, 3, and 5 years were $93,64.1$, and $40.7 \%$, respectively.

The present study results showed that the mean \pm SD age at diagnosis was $68.3 \pm 9.82$ years, and in a study in Yazd Province-Iran on 113 patients with prostate cancer was $67.3 \pm 9.82$ years the five-year survival rate was $36.1 \%$ [21].

Several studies have been conducted in Asia on the survival of PC. Between 1992 and 2000, PC's relative fiveyear survival rate in China was $32.5 \%$ [22]. However, the five-year survival rate of prostate cancer in South Korea in 1996 and between 2010 and 2014 was 67.2 and 93.3\%, respectively, which is ascending [23, 24]. Another study on different ethnic groups in China reported that the survival rate ranged from 26 to $78 \%$, which is a broad-spectrum so that there was a significant difference between different ethnic groups [25]. The survival rate of PC patients has been ascending over the past few years [26].

In all regions, the five-year survival rate increased from $83 \%$ in the late 1980 s to $99 \%$ in late 2008-2014 [27]. According to Colman et al., the five-year survival rate in 31 countries showed a wide range of changes in survival rate in different age groups in different countries. Even after adjusting to cover differences in mortality rate due to other causes, the difference was still considerable in the USA, so the survival rate of Caucasians was higher than Afro-Americans (92.4 vs. 85.8\%). The differences can be due to different care qualities and stages of disease $[28,29]$.

The Steele et al. study showed that the one-year and five-year survival rate was notably higher than previous periods like 2002-2003 and 2004-2009 [30]. Critz et al. reported a 10-year survival rate of prostate cancer in their study in 2013, approximately $75 \%$ in the USA [31], which is two times more than what was reported by a metaanalysis study on 11 studies, which was equal to $36.2 \%$ $[15,32]$. In general, one, five, and ten-year survival rates 
Table 1 Demographic and clinical characteristics of PC patients and survival using Kaplan-Meier method

\begin{tabular}{|c|c|c|c|c|}
\hline Characteristic & Category & $\mathrm{N}(\%)$ & $\begin{array}{l}\text { Median survival per (sub) category } \\
(95 \% \mathrm{Cl})\end{array}$ & ${ }^{*} P$-Value \\
\hline \multirow[t]{4}{*}{ Age at diagnosis } & $\leq 60$ years & $56(13.7)$ & $84(68-98)$ & $<0.001$ \\
\hline & $61-70$ years & $150(36.8)$ & $60(50-71)$ & \\
\hline & $71-80$ years & $143(34.6)$ & $46(37-51.5)$ & \\
\hline & $\geq 81$ years & $61(14.9)$ & $30(22-34.5)$ & \\
\hline \multirow[t]{2}{*}{ Residence } & Rural & $128(31.2)$ & $45(37-50)$ & 0.022 \\
\hline & Urban & $282(68.8)$ & $55(46-60.5)$ & \\
\hline \multirow[t]{2}{*}{ Marital status } & Single & $30(7.3)$ & $44(25-64)$ & 0.327 \\
\hline & Married & $380(92.7)$ & $49(45-55.5)$ & \\
\hline \multirow[t]{4}{*}{ Occupation } & Unemployed & $107(26.1)$ & $41(31.5-50)$ & 0.003 \\
\hline & Worker & $62(15.1)$ & $47(33-70)$ & \\
\hline & Self-employed & $207(50.5)$ & $50(46-60)$ & \\
\hline & Employee & $34(8.3)$ & $62(51-74)$ & \\
\hline \multirow[t]{3}{*}{ Education } & Illiterate & $141(34.4)$ & $44(37-48)$ & 0.002 \\
\hline & Diploma or below & $242(59)$ & $55(46.5-64)$ & \\
\hline & Academic & $27(6.6)$ & $91(80-102)$ & \\
\hline \multirow[t]{2}{*}{ Tobacco history } & No & $286(69.8)$ & $48(44-59.5)$ & 0.978 \\
\hline & Yes & $124(30.2)$ & $49(42-56)$ & \\
\hline \multirow[t]{2}{*}{ Alcohol history } & No & $399(97.3)$ & $49(45-55.5)$ & 0.568 \\
\hline & Yes & $11(2.7)$ & $51(32.5-68)$ & \\
\hline \multirow[t]{2}{*}{ Family history of $\mathrm{PC}$} & No & $362(88.3)$ & $50(46-56)$ & 0.498 \\
\hline & Yes & $48(11.7)$ & $46.5(30-70.5)$ & \\
\hline \multirow[t]{2}{*}{ Comorbidity } & No & $240(58.5)$ & $55(48-63)$ & 0.042 \\
\hline & Yes & $170(41.5)$ & $45(37-50)$ & \\
\hline \multirow[t]{4}{*}{ AJCC stage of disease } & 1 & $102(24.9)$ & $84(68.5-102)$ & $<0.001$ \\
\hline & $\|$ & $114(27.8)$ & $70(61.5-91)$ & \\
\hline & III & $152(37.1)$ & $30(26-35)$ & \\
\hline & IV & $42(10.2)$ & $24(19-26)$ & \\
\hline \multirow[t]{4}{*}{ Gleason score } & $\leq 6$ & $85(20.7)$ & $102(91-112)$ & $<0.001$ \\
\hline & 7 & $94(22.9)$ & $61(60-74)$ & \\
\hline & 8 & $114(27.8)$ & $36.5(34.5-40)$ & \\
\hline & $\geq 9$ & $117(28.5)$ & $19(17-22)$ & \\
\hline \multirow[t]{7}{*}{ Treatment } & No treatment & $30(7.3)$ & $31.5(26-35)$ & $<0.001$ \\
\hline & Active surveillance & $63(15.4)$ & $109(90-123)$ & \\
\hline & Radical Prostatectomy & $40(9.8)$ & $102(87-114)$ & \\
\hline & Radiotherapy & $87(21.2)$ & $58(51.5-64)$ & \\
\hline & $\begin{array}{l}\text { Radiotherapy + Radical Prostatec- } \\
\text { tomy }\end{array}$ & $51(12.4)$ & $49(38-67)$ & \\
\hline & Orchiectomy & $86(21)$ & $29(23-33)$ & \\
\hline & Androgen therapy & $53(12.9)$ & $22(16-26)$ & \\
\hline
\end{tabular}

$P C$ Prostate cancer, $C l$ confidence interval

* Log- rank test $-P<0.05$

of $\mathrm{PC}$ in Asian countries were less than the world mean rate. In addition, the survival rate was higher in countries with higher HDI [15]. This index is higher for Asian people living outside Asia. Improving survival rate, lead time, over diagnosis, and prostate antigen-specific antigen screening are essential factors. In addition, thanks to new treatments and interventions and an increase in HDI, the survival rate of PC patients has been increasing [27, 32].

$\mathrm{PC}$ is not prevalent in men younger than 50 years old. The results indicated a higher mortality rate in individuals diagnosed in 71-80 and above 81 years old. A study in Yazd Province-Iran on 113 patients with 


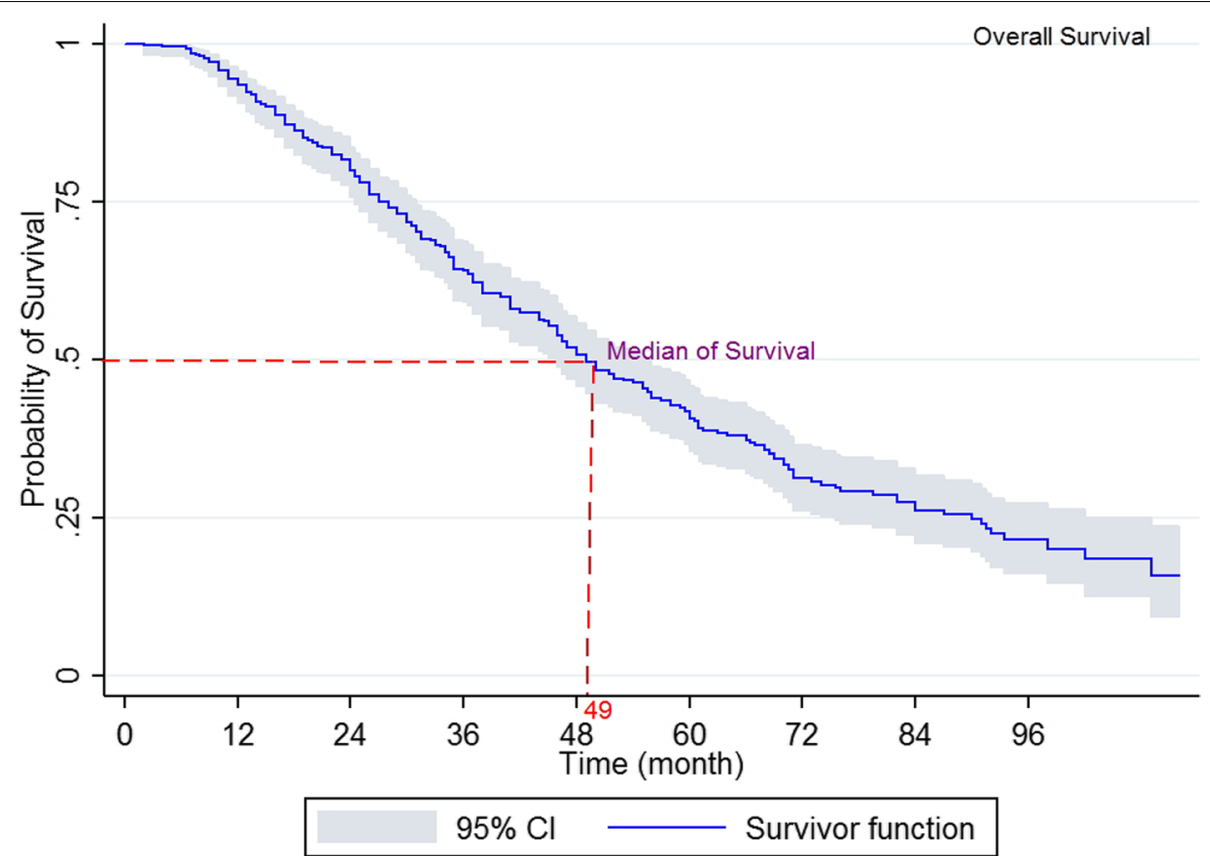

Fig. 1 Five-year survival of patients diagnosed with PC cancer in Kurdistan province (2011 - 2018) (Kaplan- Meier). PC $=$ Prostate cancer, $C l=$ confidence interval

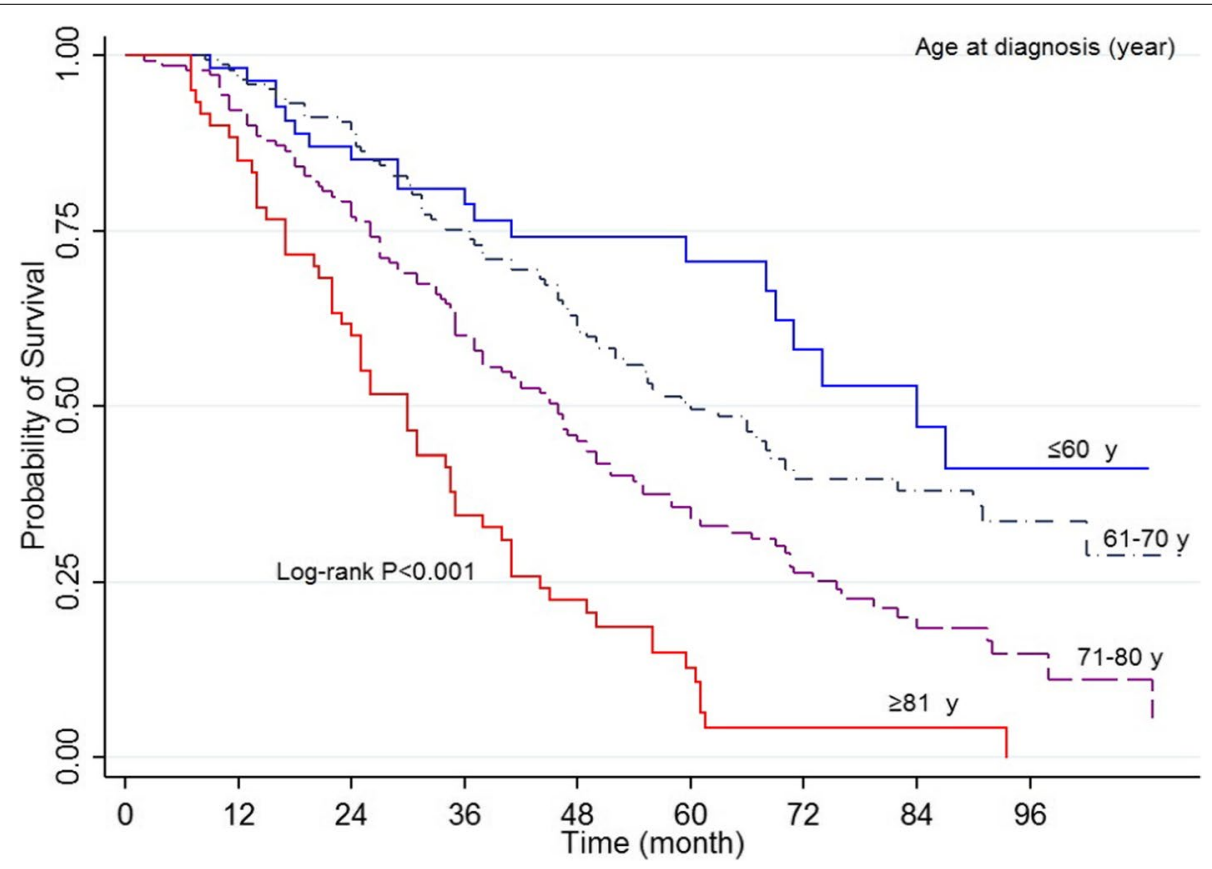

Fig. 2 Kaplan-Meier curves of prostate cancer-specific survival across age at diagnosis

prostate cancer showed that 19 patients [21\%] were younger than 60 years old. Regression results indicated that the mortality rate in $70-79$ age group $(\mathrm{HR}=3.12$, 95\% CI:1.12-8.72, $P=0.029)$ and older than 80 years old $(\mathrm{HR}=7.13,95 \mathrm{CI}: 2.50-20.189, P<0.001)$ was higher [21]. Other studies have shown that most patients with PC who survived were older than 65 years old (82\%), while less than $1 \%$ were younger than 50 years old [27, 


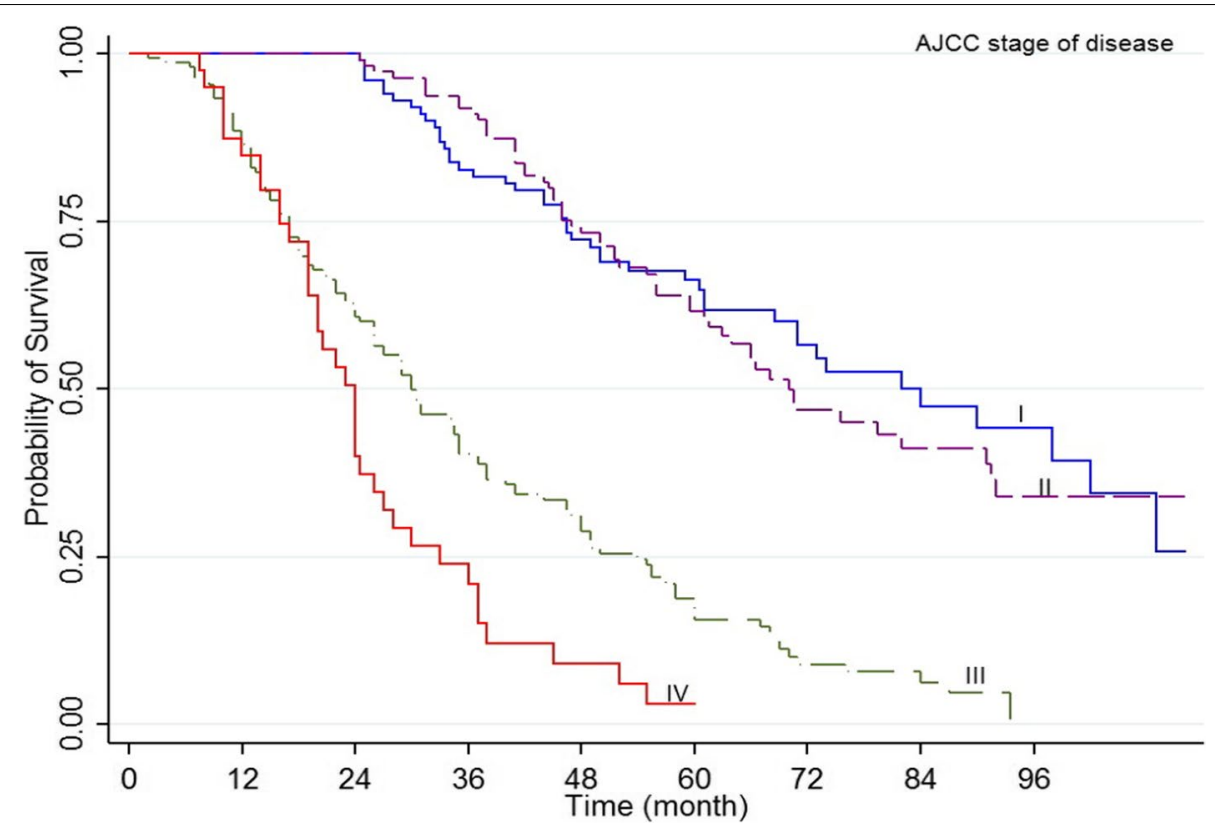

Fig. 3 Kaplan-Meier curves of prostate cancer -specific survival across AJCC stage of disease

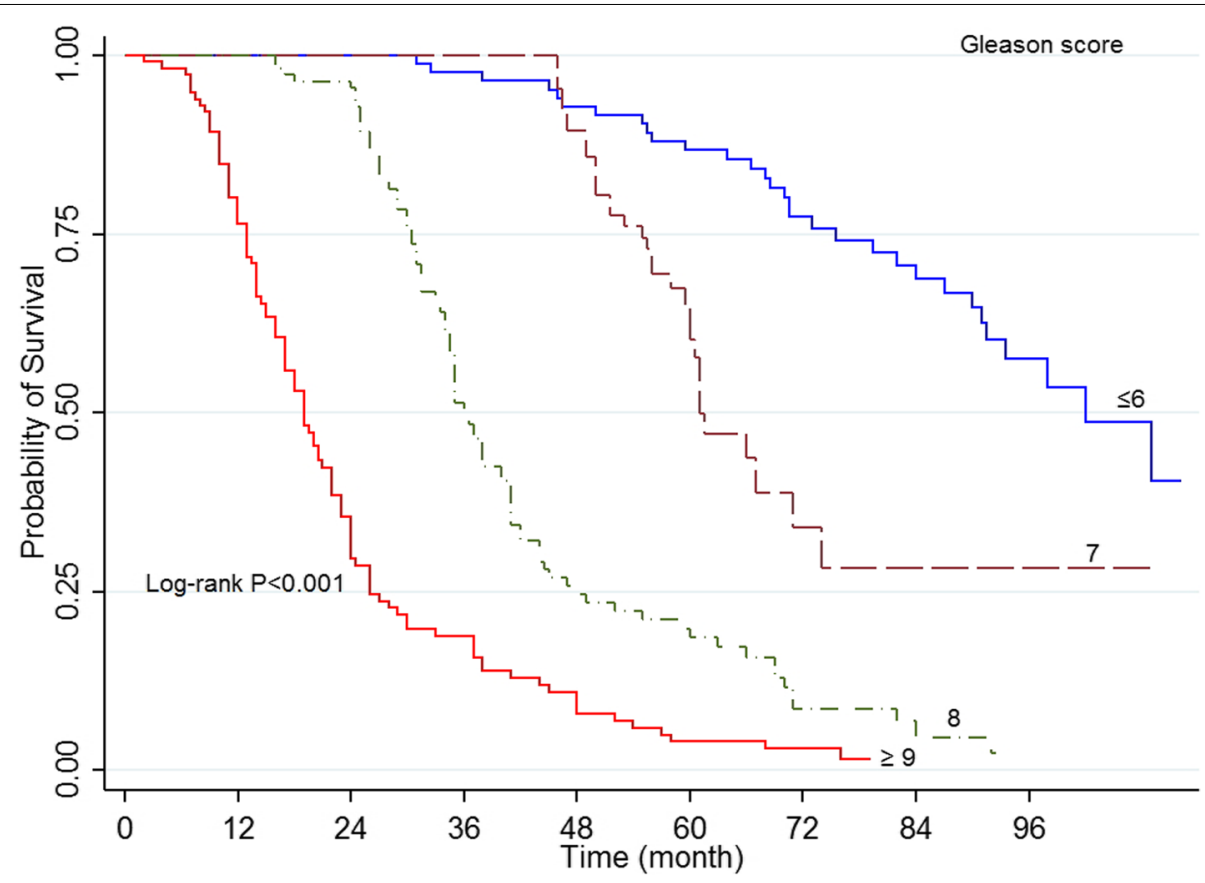

Fig. 4 Kaplan-Meier curves of prostate cancer -specific survival across Gleason score

32]. The population-based study in the United States showed that survival PC patients were more deficient among the youngest (40-44 years) and oldest patients. The lower survival among the youngest and oldest age group was mainly due to the degree and stage of the disease [33]. However, the independent effect of age on
PC survival has not been well established, and there is some evidence that age is not independently associated with specific cancer survival [34].

In Iran and Kurdistan provinces, since prostate cancer screening is not performed and people are less aware of the signs and symptoms of the disease, so at 
Table 2 Univariate and multivariate cox regression analysis for 5-year overall survival rate

\begin{tabular}{|c|c|c|c|c|c|}
\hline Characteristic & Category & $\begin{array}{l}\text { Univariate analysis } \\
\text { HR }(95 \% \mathrm{Cl})\end{array}$ & ${ }^{*} P$-Value & $\begin{array}{l}\text { Multivariate analysis } \\
\text { HR }(95 \% \mathrm{Cl})\end{array}$ & $P$-Value \\
\hline \multirow[t]{4}{*}{ Age at diagnosis } & $\leq 60$ years & 1 & - & 1 & - \\
\hline & $61-70$ years & $1.47(0.90-2.42)$ & 0.118 & $0.86(0.49-1.50)$ & 0.609 \\
\hline & $71-80$ years & $2.44(1.57-3.95)$ & $<0.001$ & $1.26(1.12-2.31)$ & $0.032^{*}$ \\
\hline & $\geq 81$ years & $4.99(2.98-8.36)$ & $<0.001$ & $2.33(1.23-4.42)$ & $0.009^{*}$ \\
\hline \multirow[t]{2}{*}{ Residence } & Rural & 1 & - & 1 & - \\
\hline & Urban & $0.74(0.57 .0 .96)$ & 0.024 & $0.98(0.74-1.23)$ & 0.067 \\
\hline \multirow[t]{2}{*}{ Marital status } & Single & 1 & - & Not in model & - \\
\hline & Married & $0.80(0.51-1.25)$ & 0.331 & - & - \\
\hline \multirow[t]{4}{*}{ Occupation } & Unemployed & 1 & - & 1 & - \\
\hline & Worker & $0.80(0.55-1.17)$ & 0.268 & $1.09(0.71-1.68)$ & 0.683 \\
\hline & Self-employed & $0.74(0.55-0.99)$ & 0.043 & $1.01(0.74-1.38)$ & 0.967 \\
\hline & Employee & $0.28(0.15-0.52)$ & $<0.001$ & $0.42(0.20-0.87)$ & $0.021^{*}$ \\
\hline \multirow[t]{3}{*}{ Education } & Illiterate & 1 & - & 1 & - \\
\hline & Diploma or below & $0.83(0.71-0.93)$ & 0.042 & $0.91(0.64-1.11)$ & 0.087 \\
\hline & Academic & $0.36(0.19-0.68)$ & 0.002 & $0.78(0.64-0.91)$ & $0.042^{*}$ \\
\hline \multirow[t]{2}{*}{ Tobacco history } & No & 1 & - & Not in model & - \\
\hline & Yes & $0.99(0.76-1.29)$ & 0.978 & - & - \\
\hline \multirow[t]{2}{*}{ Alcohol history } & No & 1 & - & Not in model & \\
\hline & Yes & $0.78(0.35-1.77)$ & 0.568 & - & - \\
\hline \multirow[t]{2}{*}{ Family history of PC } & No & 1 & & Not in model & - \\
\hline & Yes & $1.13(0.78-1.65)$ & 0.498 & - & - \\
\hline \multirow[t]{2}{*}{ Comorbidity } & No & 1 & & 1 & - \\
\hline & Yes & $1.28(1.01-1.63)$ & 0.044 & $1.05(0.85-1.14)$ & 0.124 \\
\hline \multirow[t]{4}{*}{ AJCC stage of disease } & 1 & 1 & & 1 & \\
\hline & $\|$ & $1.09(0.74-1.62)$ & 0.634 & $1.03(0.61-1.40)$ & 0.733 \\
\hline & III & $4.38(3.09-6.20)$ & $<0.001$ & $1.45(1.09-2.30)$ & $0.045^{*}$ \\
\hline & IV & $8.55(5.41-13.53)$ & $<0.001$ & $2.18(1.09-3.68)$ & $0.025^{*}$ \\
\hline \multirow[t]{4}{*}{ Gleason score } & $\leq 6$ & 1 & & 1 & - \\
\hline & 7 & $2.19(1.31-3.63)$ & 0.002 & $1.21(0.69-1.40)$ & 0.501 \\
\hline & 8 & $5.32(2.34-8.97)$ & $<0.001$ & $4.16(2.50-6.93)$ & $0.012^{*}$ \\
\hline & $\geq 9$ & $8.14(5.32-11.64)$ & $<0.001$ & $7.12(5.35-10.28)$ & $0.002^{*}$ \\
\hline \multirow[t]{7}{*}{ Treatment } & No treatment & 1 & & 1 & - \\
\hline & Active surveillance & $0.06(0.03-0.11)$ & $<0.001$ & $0.14(0.07-0.29)$ & $0.001^{*}$ \\
\hline & Radical Prostatectomy & $0.07(0.03-0.13)$ & $<0.001$ & $0.16(0.08-0.37)$ & $0.001^{*}$ \\
\hline & Radiotherapy & $0.25(0.15-0.40)$ & $<0.001$ & $0.48(0.28-0.83)$ & $0.008^{*}$ \\
\hline & $\begin{array}{l}\text { Radiotherapy + Radical } \\
\text { Prostatectomy }\end{array}$ & $0.34(0.20-0.57)$ & $<0.001$ & $0.42(0.23-0.76)$ & $0.005^{*}$ \\
\hline & Orchiectomy & $1(0.64-1.56)$ & 0.977 & $0.48(0.29-0.81)$ & $0.006^{*}$ \\
\hline & Androgen therapy & $0.97(0.85-1.20)$ & 0.185 & $0.68(0.39-1.17)$ & 0.169 \\
\hline
\end{tabular}

older ages, they go for diagnosis and treatment, which has a more advanced grade and stage of the tumor.

There was no significant relationship between smoking and drinking history and survival of prostate cancer; socioeconomic condition was not checked in this study. Other studies in Kurdistan Province have demonstrated a higher mortality rate in lower socioeconomic conditions in patients with colorectal cancer [35]. Some studies have argued that the higher mortality rate in lower socioeconomic groups is due to the higher prevalence of comorbidity in these people [36]. Co-morbidity and other factors can describe this finding. For example, high-risk behaviors such as smoking and drinking are more common in lower socioeconomic groups, partially explaining the lower survival rate in these groups [37, 38]. A study by $\mathrm{Xu}$ et al. in China illustrated that there was a 
significant difference between PC patients with hypertension (28.5\%) and a control group (48.3\%) in terms of five-year survival rate [39]. Co-morbidity increases the risk of all-cause mortality but not cancer-specific mortality; this may be since co-morbidity increases the risk of death due to non-cancer causes between PC patients. It is evident that co-morbidity influences the survival of patients due to deaths from other causes than cancer and affects the decision-making process of treatment.

The results showed the hazard rate in individuals with a Gleason score of $8(\mathrm{HR}=4.16)$ and individuals with a Gleason score $\geq$ of $9(\mathrm{HR}=7.12)$. A study in Iran on people with Gleason scores of 7 and 8-10 reported $H R=1.87$ (95\%CI:1.13-3.11, $P=0.014)$ and $\mathrm{HR}=2.38$ (95\% CI 1.14$4.98, P=0.021)$ respectively [21]. Gleason's ranking system for PC measures the invasiveness of cancer. A higher score indicates more invasive cancer and a higher risk of metastasis. It is known that this ranking system is directly related to mortality rate and predicts recurrence after surgery and response to treatment [40].

As the results showed, the HR of the cases with tumor stage III was equal to 1.45 , and that of patients with tumor stage IV was equal to 2.18 . More than $90 \%$ of PC cases are diagnosed in the early stages, so relative fiveyear survival is close to $100 \%$ (tumor staging data are not accurately recorded). However, five-year survival in patients with advanced tumor stage decreased by $30 \%$. The histologic level of PC is essential for prognosis. Therefore, it is recommended to report both Gleason's score and cohort score. The PSA level of the serum completes the clinical examination, TNM and group level, and the AJCC prognostic stage group can be defined [41].

Uni and multivariate regression analyses showed that patients who received active surveillance, radical prostatectomy; radiotherapy; combined treatment; and orchiectomy had a higher survival rate than patients who did not receive any treatment, indicating the effect of treatment on survival. A study on 9772 PC patients between 2010 and 2015 in Iran showed that the patients who had radiotherapy and surgery had $92 \%$ five-year survival, while this figure for those without treatment was 67.5\% [42].

In the study, Kenrick et al. median overall survival for the total cohort was 25.5 months in black men vs. 21.8 months' white men ( $\mathrm{HR}=0.81, P=0.08)$ with metastatic castration-resistant prostate cancer. There was prolonged survival in the black population in those who only received hormone-based treatment throughout their treatment course; 39.7 months black vs. 17.1 months white $(\mathrm{HR}=0.54, P=0.019)$ [43].

The result of a population-based cohort study showed, In age-adjusted and multivariable-adjusted analyses, statin use after ADT was associated with a decreased risk of prostate cancer death ( $\mathrm{HR}=0.82 ; 0.95 \%$ CI 0.69-0.96) [44].
Based on the severity of the disease, some patients might need combined treatments along with radical prostatectomy followed by radiotherapy or ADT with radiotherapy. The type of treatment can be determined depending on age, race, ethnic group, access to oncology services, and socioeconomic condition [45].

Treatment can affect the survival rate of cancer patients, while there is ambiguous evidence about the effect of treatment methods on survival rate. Largescale trial studies on men with PC in the early stages of PSA showed that the advantages of radical treatment are higher than active surveillance. However, further examinations in different situations did not support such advantages. It is not easy to conclude that treatment affects the survival rate $[46,47]$.

PC treatment depends on the risk of the progress of the disease, co-morbidity, patient's preferences, and physician's decision. There has been an improvement in the survival rate of PC patients in the UK over the past two decades. Still, survival rate inequality based on socioeconomic has been reported by some studies in the UK, Wales, and Scotland [17].

A meta-analysis study on the survival rate of PC patients in Asia showed that the highest survival rate was in Asian people living in the UK, followed by Japanese. On the other hand, China had the lowest one-year survival rate. Higher HDI is related to a higher survival rate as countries like Japan and Singapore with higher HDI had a higher survival rate. That is not true in India as, although the survival rate is high, HDI in India is lower than that of China [15]. These differences can be explained by differences in the health education program and the quality of diagnostic and treatment services and follow-ups [17].

A wide range of factors can affect prostate cancer survival in less developed regions, such as diagnosis age, stage of the disease, invasiveness of the disease, co-morbidity, and unhealthy habits [48].

Many factors have been investigated for their role in PC survival. Evidence on the role of age and race provided inconsistent results, while socioeconomic status, tumor-related characteristics, and treatment had a main role in PC survival.

Essential factors in the difference in prostate cancer survival rate in Kurdistan province can be the lack of prostate cancer screening, lack of awareness of the symptoms of the disease, late referral of patients (diagnosis of disease in old age), and tumor progression is. Another critical aspect of socioeconomic status is accessing the health care services and quality of testing services available to different socioeconomic groups. These vary in different countries. Also, non-academic education, occupation (worker, farmer), and living in rural areas affect the low survival of prostate 
cancer in Kurdistan province compared to other regions and countries.

\section{Conclusion}

This study demonstrated that factors such as age at diagnosis, level of education, occupation, AJCC stage of disease, Gleason score, and type of treatments were influential factors in the survival of PC patients in Kurdistan province and needed more attention.

\section{Acknowledgments}

The authors would like to thank the Clinical Research Development Center, Kowsar Hospital of Kurdistan University of Medical Sciences.

\section{Authors' contributions}

MAR, GM, and HS conceived and designed the study. MAR, HS and GM analyzed and interpreted the data and drafted the manuscript. MAR, GM, HS, $B Z, S T, H Z, F G, S S, P H$ and MM were involved in the composition of the study tool, collect data, supervision of the research process, and critical revision and review of the manuscript. All the authors read and approved the final manuscript.

\section{Funding}

Vice-Chancellor funded this study for Research and Technology of Kurdistan University of Medical Sciences, Sanandaj, Iran.

\section{Availability of data and materials}

The datasets used and analyzed during the current study are available from the corresponding author on reasonable request.

\section{Declarations}

\section{Ethics approval and consent to participate}

The Ethics Committee of Kurdistan University of Medical Sciences (IR.MUK. REC.1397.67) reviewed and approved this study (IR. All patients provided written informed consents. The relevant guidelines and regulations performed all methods.

\section{Consent for publication}

Not applicable

\section{Competing interests}

The authors declare that they have no competing interests.

\section{Author details}

${ }^{1}$ Social Determinants of Health Research Center, Research Institute for Health Development, Kurdistan University of Medical Sciences, Sanandaj, Iran. ${ }^{2}$ Department of Epidemiology and Biostatistics, Faculty of Medicine, Kurdistan University of Medical Sciences, Sanandaj, Iran. ${ }^{3}$ Department of Epidemiology, School of Public Health, Hamadan University of Medical Sciences, Hamadan, Iran. ${ }^{4}$ Department of Urology, Faculty of Medicine, Kurdistan University of Medical Sciences, Sanandaj, Iran. ${ }^{5}$ Department of Biological Sciences, Faculty of Science, University of Kurdistan, Sanandaj, Iran. ${ }^{6}$ Department of Epidemiology, School of Public Health, Iran University of Medical Sciences, Tehran, Iran. ${ }^{7}$ Department of Clinical Biochemistry, School of Medicine, Urmia University of Medical Sciences, Urmia, Iran.

Received: 20 May 2021 Accepted: 29 November 2021

Published online: 08 December 2021

\section{References}

1. Rawla P. Epidemiology of prostate cancer. World J Oncol. 2019;10(2):6389. https://doi.org/10.14740/wjon1191.

2. Bray F, Ferlay J, Soerjomataram I, Siegel RL, Torre LA, Jemal A. Global cancer statistics 2018: GLOBOCAN estimates of incidence and mortality worldwide for 36 cancers in 185 countries. CA Cancer I Clin. 2018;68(6):394-424.

3. Culp MB, Soerjomataram I, Efstathiou JA, Bray F, Jemal A. Recent global patterns in prostate cancer incidence and mortality rates. Eur Urol. 2020;77(1):38-52.

4. Panigrahi GK, Praharaj PP, Kittaka H, Mridha AR, Black OM, Singh R, et al. Exosome proteomic analyses identify inflammatory phenotype and novel biomarkers in African American prostate cancer patients. Cancer Med. 2019:8(3):1110-23.

5. Mojahedian MM, Toroski M, Keshavarz K, Aghili M, Zeyghami S, Nikfar S. Estimating the cost of illness of prostate cancer in Iran. Clin Ther. 2019;41(1):50-8.

6. Moradi A, Zamani M, Moudi E. A systematic review and meta-analysis on incidence of prostate cancer in Iran. Health Promot Perspect. 2019;9(2):92.

7. Pakzad R, Rafiemanesh H, Ghoncheh M, Sarmad A, Salehiniya H, Hosseini $\mathrm{S}$, et al. Prostate cancer in Iran: trends in incidence and morphological and epidemiological characteristics. Asian Pac J Cancer Prev. 2016;17(2):839-43.

8. Bhardwaj A, Srivastava SK, Khan MA, Prajapati VK, Singh S, Carter JE, et al. Racial disparities in prostate cancer: a molecular perspective. Front Biosci. 2017:22:772.

9. Friedlander DF, Trinh Q-D, Krasnova A, Lipsitz SR, Sun M, Nguyen PL, et al. Racial disparity in delivering definitive therapy for intermediate/high-risk localized prostate cancer: the impact of facility features and socioeconomic characteristics. Eur Urol. 2018;73(3):445-51.

10. Odedina FT, Akinremi TO, Chinegwundoh F, Roberts R, Yu D, Reams RR, et al. Prostate cancer disparities in Black men of African descent: a comparative literature review of prostate cancer burden among Black men in the United States, Caribbean, United Kingdom, and West Africa. Infect Agents Cancer. 2009:4(1):1-8.

11. Chamie K, Connor SE, Maliski SL, Fink A, Kwan L, Litwin MS, editors. Prostate cancer survivorship: lessons from caring for the uninsured. Urologic Oncology: Seminars and Original Investigations; 2012: Elsevier.

12. Draisma G, Etzioni R, Tsodikov A, Mariotto A, Wever E, Gulati R, et al. Lead time and overdiagnosis in prostate-specific antigen screening: importance of methods and context. J Natl Cancer Inst. 2009;101(6):374-83.

13. Etzioni R, Gulati R, Tsodikov A, Wever EM, Penson DF, Heijnsdijk EA, et al. The prostate cancer conundrum revisited: treatment changes and prostate cancer mortality declines. Cancer. 2012;118(23):5955-63.

14. Skolarus TA, Wolf AM, Erb NL, Brooks DD, Rivers BM, Underwood W III, et al. American Cancer Society prostate cancer survivorship care guidelines. CA Cancer J Clin. 2014;64(4):225-49.

15. Hassanipour S, Delam H, Arab-Zozani M, Abdzadeh E, Hosseini SA, Nikbakht $\mathrm{H}-\mathrm{A}$, et al. Survival rate of prostate cancer in Asian countries: a systematic review and meta-analysis. Ann Glob Health. 2020;86(1).

16. Chirlaque M, Salmerón D, Galceran J, Ameijide A, Mateos A, Torrella $A$, et al. Cancer survival in adult patients in Spain. Results from nine population-based cancer registries. Clin Transl Oncol. 2018;20(2):201-11.

17. Shack L, Rachet B, Brewster D, Coleman M. Socioeconomic inequalities in cancer survival in Scotland 1986-2000. Br J Cancer. 2007;97(7):999-1004.

18. Tibshirani R. The lasso method for variable selection in the Cox model. Stat Med. 1997;16(4):385-95.

19. EW S. Clinical prediction models: a practical approach to development, validation, and updating, vol. 2009. New York: Springer; 2009. p. 53.99.

20. Kleinbaum DGKM. Survival analysis: a self-learning text. New York: Springer Science \& Business Media; 2006.

21. Zahir ST, Nazemian MR, Zand S, Zare S. Survival of patients with prostate cancer in Yazd, Iran. Asian Pac J Cancer Prev. 2014;15(2):883-6.

22. Chen J, Zhu J, Zhang Y, Lu J. Cancer survival in Qidong, China, 1992-2000. IARC Sci Publ. 2011;2011(162):43-53.

23. Jung K-W, Park S, Kong H-J, Won Y-J, Lee JY, Park E-C, et al. Cancer statistics in Korea: incidence, mortality, survival, and prevalence in 2008. Cancer Res Treatment. 2011:43(1):1.

24. Jung K-W, Won Y-J, Kong H-J, Oh C-M, Lee DH, Lee JS. Cancer statistics in Korea: incidence, mortality, survival, and prevalence in 2011. Cancer Res Treatment. 2014;46(2):109.

25. Wang F, Feng J, Chen P, Liu X, Ma M, Zhou R, et al. Probiotics in Helicobacter pylori eradication therapy: systematic review and network metaanalysis. Clin Res Hepatol Gastroenterol. 2017;41(4):466-75. 
26. Chen S-L, Wang S-C, Ho C-J, Kao Y-L, Hsieh T-Y, Chen W-J, et al. Prostate cancer mortality-to-incidence ratios are associated with cancer care disparities in 35 countries. Sci Rep. 2017;7(1):1-6.

27. Miller KD, Nogueira L, Mariotto AB, Rowland JH, Yabroff KR, Alfano CM, et al. Cancer treatment and survivorship statistics, 2019. CA Cancer J Clin. 2019;69(5):363-85.

28. Bekelman JE, Rumble RB, Chen RC, Pisansky TM, Finelli A, Feifer A, et al. Clinically localized prostate cancer: ASCO clinical practice guideline endorsement of an American Urological Association/American Society for Radiation Oncology/Society of Urologic Oncology guideline. J Clin Oncol. 2018;36(32):3251-8.

29. Coleman MP, Quaresma M, Berrino F, Lutz J-M, De Angelis R, Capocaccia $\mathrm{R}$, et al. Cancer survival in five continents: a worldwide population-based study (CONCORD). Lancet Oncol. 2008;9(8):730-56.

30. Steele CB, Li J, Huang B, Weir HK. Prostate cancer survival in the United States by race and stage (2001-2009): Findings from the CONCORD-2 study. Cancer. 2017;123:5160-77.

31. Critz FA, Benton JB, Shrake P, Merlin ML. 25-Year disease-free survival rate after irradiation for prostate cancer calculated with the prostate specific antigen definition of recurrence used for radical prostatectomy. J Urol. 2013;189(3):878-83.

32. Noone A, Howlader N, Krapcho M, Miller D, Brest A, Yu M, et al. SEER cancer statistics review, 1975-2015. Bethesda: National Cancer Institute; 2018. p. 4.

33. Merrill RM, Bird JS. Effect of young age on prostate cancer survival: a population-based assessment (United States). Cancer Causes Control. 2002;13(5):435-43.

34. Bechis SK, Carroll PR, Cooperberg MR. Impact of age at diagnosis on prostate cancer treatment and survival. J Clin Oncol. 2011:29(2):235.

35. Rasouli MA, Moradi G, Roshani D, Nikkhoo B, Ghaderi E, Ghaytasi B. Prognostic factors and survival of colorectal cancer in Kurdistan province, Iran: a population-based study (2009-2014). Medicine. 2017;96(6).

36. Clark LC, Combs GF, Turnbull BW, Slate EH, Chalker DK, Chow J, et al. Effects of selenium supplementation for cancer prevention in patients with carcinoma of the skin: a randomized controlled trial. JAMA. 1996;276(24):1957-63.

37. Jeffreys M, Sarfati D, Stevanovic V, Tobias M, Lewis C, Pearce N, et al. Socioeconomic inequalities in cancer survival in New Zealand: the role of extent of disease at diagnosis. Cancer Epidemiol Prevent Biomark. 2009;18(3):915-21.

38. Lawder R, Harding O, Stockton D, Fischbacher C, Brewster DH, Chalmers J, et al. Is the Scottish population living dangerously? Prevalence of multiple risk factors: the Scottish Health Survey 2003. BMC Public Health. 2010;10(1):1-13.

39. Xu H, Zhang L-m, Liu J, Ding G-x, Ding Q, Jiang H-w. The association between overall survival of prostate cancer patients and hypertension, hyperglycemia, and overweight in Southern China: a prospective cohort study. J Cancer Res Clin Oncol. 2013;139(6):943-51.

40. Thompson I, Thrasher JB, Aus G, Burnett AL, Canby-Hagino ED, Cookson MS, et al. Guideline for the management of clinically localized prostate cancer: 2007 update. J Urol. 2007;177(6):2106-31.

41. Buyyounouski MK, Choyke PL, McKenney JK, Sartor O, Sandler HM, Amin $\mathrm{MB}$, et al. Prostate cancer-major changes in the American Joint Committee on Cancer eighth edition cancer staging manual. CA Cancer J Clin. 2017:67(3):245-53.

42. Aliakbari F, Ghanbari MA, Khayamzadeh M, Hajian MR, Allameh F, Ahadi $M$, et al. Five-year Survival Rate of Prostate Cancer in Iran: Results of the national cancer-registry system during 2010-2015. Mens Health J. 2020;4(1):e4.

43. Ng K, Wilson P, Mutsvangwa K, Hounsome L, Shamash J. Overall survival of black and white men with metastatic castration-resistant prostate cancer (MCRPC): a 20-year retrospective analysis in the largest healthcare trust in England. Prostate Cancer Prostatic Dis. 2021:1-7.

44. Peltomaa A, Raittinen P, Talala K, Taari K, Tammela T, Auvinen A, et al. Prostate cancer prognosis after initiation of androgen deprivation therapy among statin users. A population-based cohort study. Prostate Cancer Prostatic Dis. 2021:1-8.

45. Lin GA, Aaronson DS, Knight SJ, Carroll PR, Dudley RA. Patient decision aids for prostate cancer treatment: a systematic review of the literature. CA Cancer J Clin. 2009;59(6):379-90.
46. Bill-Axelson A, Holmberg L, Ruutu M, Häggman M, Andersson S-O, Bratell $\mathrm{S}$, et al. Radical prostatectomy versus watchful waiting in early prostate cancer. N Engl J Med. 2005;352:1977-84.

47. Wilt TJ, Brawer MK, Jones KM, Barry MJ, Aronson WJ, Fox S, et al. Radical prostatectomy versus observation for localized prostate cancer. N Engl J Med. 2012;367:203-13.

48. Mokete M, Shackley DC, Betts CD, O'FLYNN KJ, Clarke NW. The increased rate of prostate specific antigen testing has not affected prostate cancer presentation in an inner city population in the UK. BJU Int. 2006;97(2):266-9.

\section{Publisher's Note}

Springer Nature remains neutral with regard to jurisdictional claims in published maps and institutional affiliations.
Ready to submit your research? Choose BMC and benefit from:

- fast, convenient online submission

- thorough peer review by experienced researchers in your field

- rapid publication on acceptance

- support for research data, including large and complex data types

- gold Open Access which fosters wider collaboration and increased citations

- maximum visibility for your research: over 100M website views per year

At BMC, research is always in progress.

Learn more biomedcentral.com/submissions 